\title{
A farmer's perception of practical seed production requirements
}

\author{
JOHN MCKAY
}

Farmer, Ashburton

Perhaps just as strange to many grassland farmers as a cow jumping over the moon, would be a farming enterprise in which a combine harvester covers every hectare of the farm in order to gather the income for the business. But this is the lot of the MidCanterbury seed producer.

Seed production on a specialist Mid-Canterbury farm can be divided into three main operations: planning, growing the crop, then harvesting and handling.

\section{Planning}

The farmer must first consider meeting the requirements of quality production as laid down by the Seed Certification scheme. This quality assurance scheme ensures seed which is true to type and free of weeds and diseases.

In planning to produce a particular seed crop, the history, potential contaminants in the field, the number of years between successive crops, suitable break in crops, isolation, weed problems, fertility status, soil structure and the expected stand life are all factors in deciding the suitability of an individual field for a particular crop.

For example, a field suitable for the production of a new cultivar of white clover would have no other clover variety for the previous 5 years, a buried seedcount test of the soil. a 50 metre isolation from other clover varieties, and 3 field inspections by the MAE.

The equipment and storage facilities, labour and capital requirements of growing the crop are also considerations before planting.

\section{Growing the crop}

A farmer's management practices for each crop are usually the result of information gathered and practical experiences, but of prime importance is an understanding of the growth pattern of the species and cultivar to be grown. This is required in order to develop a successful programme involving:

- Time of sowing: autumn or spring.

- Method of sowing: broadcast, drilling, row spacing, sowing rate.

- Fertiliser applications: type, timing and quantities of particular elements and $\mathrm{pH}$ and lime required. - Irrigation: if available, requirements and timing. - Weed and pest control.
- Fungicide requirements.

- Growth regulating chemicals which have some application in preventing crop lodging.

- Grazing managements: useful in some crops.

In general, the two most important stages of the crop growth cycle which influence the quantity and quality of seed produced, are the tillering and seedhead initiation stage and pollination/seed fill stage. The management should optimise the number of large seed-heads being produced, obtaining maximum pollination and a stress-free seedfill period.

High yields of seed from plants bred for leaf production may require manipulation of the growing plant.

For example, where the aim is to produce a large number of seed-producing tillers, nitrogen applied before tillering will stimulate an increased number of larger tillers.

The next aim is to produce a large seed-head in each tiller: nitrogen applied before seed-head initiation at the tiller base is therefore required to ensure large heads are formed.

These extra nitrogen applications can cause larger numbers of larger heads, often more than the plant can physically hold upright. Therefore, in some instances the application of growth regulator will be beneficial. Growth regulating agents generally shorten and thicken the stems.

With the extra bulk of green leaf and stem, extra care and attention needs to be paid to the build-up of pest and diseases. Hence fungicide timing is an important aspect of specialist seed producers, particularly for rust control.

Quality producers pay particular attention to purity in the field. The age-old hand-roguing of seed crops to remove contaminants and off-types is common on high-quality seed production farms.

\section{Harvesting and handling}

"It is in the last lap that the race is won or lost." This is very much the case with seed production, as just at harvest is all the farmer's planning, physical effort and capital commitment completed and the potential of his return established. Harvesting and handling, therefore, must ensure the saving of every possible seed and the keeping of the seedlot in a viable state in subsequent storage. 
This process involves:

Precise timing of cutting the crop. This is determined by moisture testing, experience-based assessment and an eye on the weather conditions.

Drying time in the field. This can be manipulated in some crops such as white clover with the use of desiccant sprays. The goal is to bring the seed to a dryness at which it can be safely handled with seed storage facilities available. This moisture content is usually less than 12\%. Harvesting at higher moisture contents is possible only with reliable and efficient drying facilities.

Picking up and threshing. In most crops the dry crop lying in the field is very vulnerable to seed shatter. Consequently, a gentle process of lifting the crop into the combine is essential. Careful attention is paid to the setting of the combine in order to thresh all of the seed without causing physical damage to individual seeds. Changes to combine setting may be required as the weather and crop conditions change throughout the day.

On our property, old binders and stooking are used to save cocksfoot seed, which is difficult to handle prior to threshing.
I have endeavoured to convey to you the precision and diligence which the Mid-Canterbury seed producer applies to his livelihood of producing quality seeds.

We pride ourselves, on our role in the seed to feed industry.

The New Zealand grasslands sector looks enthusiastically to the future which the exciting new herbage cultivars will bring to livestock production.

If you as the breeders, the advisors and the livestock farmers are to make these outstanding achievements in livestock production, you will require quality, certified seed of these new cultivars.

Not bushburn, 2nds or sweepings but high quality certified seed of the new and improved species.

Seed from the high standards of planning, husbandry, harvesting and handling, typical of the Mid-Canterbury specialist producer of seed. ("If you don't farm for a good year you'll never have one.") 